\title{
WILEY-VCH
}

DOI: $10.1002 /(($ please add manuscript number $))$

Article type: Full Paper

\section{High-Performance Inverted Planar Heterojunction Perovskite Solar Cells Based on Lead Acetate Precursor with Efficiency Exceeding 18\%}

Lichen Zhao, Deying Luo, Jiang Wu, Qin Hu, Wei Zhang, Ke Chen, Tanghao Liu, Yi Liu, Yifei Zhang, Feng Liu, Thomas P. Russell, * Henry J. Snaith, Rui Zhu, * and Qihuang Gong

L. Zhao, D. Luo, J. Wu, Q. Hu, K. Chen, T. Liu, Y. Liu, Y. Zhang, Prof. R. Zhu, Prof. Q. Gong

State Key Laboratory for Artificial Microstructure and Mesoscopic Physics, Department of Physics, Peking University, Beijing, 100871, China

E-mail: iamzhurui@pku.edu.cn (R. Zhu)

Q. Hu, Prof. R. Zhu, Prof. Q. Gong

Collaborative Innovation Center of Quantum Matter, Beijing, 100871, China

Prof. R. Zhu, Prof. Q. Gong

Collaborative Innovation Center of Extreme Optics, Shanxi University, Taiyuan,

Shanxi,030006, China

Q. Hu, Dr. F. Liu, Prof. T. P. Russell

Materials Sciences Division, Lawrence Berkeley National Laboratory, CA, 94720, USA

Prof. T. P. Russell

Department of Polymer Science and Engineering, University of Massachusetts, Amherst, MA 01003, USA

Email: russell@mail.pse.umass.edu (T.P. Russell)

Dr. W. Zhang, Prof. H. J. Snaith

Clarendon Laboratory, Department of Physics, University of Oxford, Parks, Oxford, UK

Dr. W. Zhang

School of Chemistry, University of Lincoln, Beevor Street, Lincoln LN6 7DL, UK

Keywords: perovskite solar cells, inverted planar heterojunction, lead acetate, additive, high efficiency

Abstract: Organic-inorganic lead halide perovskites are emerging materials for the nextgeneration photovoltaics. Lead halides are the most commonly used lead precursors for perovskite active layers. Recently, lead acetate $\left(\mathrm{Pb}(\mathrm{Ac})_{2}\right)$ has shown its superiority as the potential replacement for traditional lead halides. Here, we demonstrate a strategy to improve the efficiency for the perovskite solar cell based on lead acetate precursor. We utilized methylammonium bromide as an additive in the $\mathrm{Pb}(\mathrm{Ac})_{2}$ and methylammonium iodide precursor solution, resulting in uniform, compact and pinhole-free perovskite films. We 


\section{WILEY-VCH}

observed enhanced charge carrier extraction between the perovskite layer and charge collection layers and delivered a champion power conversion efficiency of $18.3 \%$ with a stabilized output efficiency of $17.6 \%$ at the maximum power point. The optimized devices also exhibited negligible current density-voltage $(J-V)$ hysteresis under the scanning conditions.

\section{Introduction}

As emerging photovoltaic materials, organic-inorganic lead halide perovskites (e.g. $\mathrm{CH}_{3} \mathrm{NH}_{3} \mathrm{PbI}_{3}$ ) have attracted much attention since their initial application in dye sensitized solar cells in $2009 .{ }^{[1]}$ The unique merits, including the excellent optical absorption, ${ }^{[2]}$ the longbalanced carrier diffusion length ${ }^{[3,4]}$ and the low-cost processing methods, ${ }^{[5]}$ have allowed them to be extremely promising for the next-generation photovoltaics. To date, the power conversion efficiencies (PCEs) have exceeded $20 \%$ for the perovskite solar cells with mesoporous structures, ${ }^{[6,7]}$ which were achieved by optimizing the device fabrication process, as well as developing composite perovskite materials.

In addition to the mesoporous strucutres, ${ }^{[8,9]}$ planar heterojunction perovskite solar cells have been also developed. ${ }^{[10]}$ To ensure the high device performance, the photoactive layer in the planar heterojunction perovskite solar cell should be a pinhole-free and compact film with 
uniform coverage and well-defined crystallinity. ${ }^{[1]}$ The perovskite $\mathrm{CH}_{3} \mathrm{NH}_{3} \mathrm{PbI}_{3}$ precursor solutions are usually prepared through the reaction of methylammonium iodide (MAI) with the lead halides $\left(\mathrm{PbI}_{2}\right.$ or $\left.\mathrm{PbCl}_{2}\right)$ in orgainic solvents such as DMF or DMSO ${ }^{[12,13]}$ In the conventional "one-step" deposition process for planar perovskite layer, the lead halide-based precursor solutions often produce the non-ideal film quality in terms of morphorlogy and crystallinity which limits the enhancement of device performance. ${ }^{[14,15]}$ To address these issues, many approaches have been developed to improve the perovskite thin film quality, such as vapor phase deposition, ${ }^{[16]}$ "two-step" sequential deposition, ${ }^{[17,18]}$ solvent engineering, ${ }^{[12,19]}$ precursor composition engineering ${ }^{[20]}$ and methylamine (MA) induced defect-healing. ${ }^{[21]}$

As an alternative strategy, efforts were also made to replace the lead halide precursors in the simple "one-step" deposition process. For example, $\mathrm{Pb}(\mathrm{SCN})_{2}{ }^{[22]}$ and $\mathrm{Pb}\left(\mathrm{NO}_{3}\right)_{2}{ }^{[23]}$ have been used as lead sources for perovskite films, although the device performances were not high. Recently, lead acetate $\left(\mathrm{Pb}(\mathrm{Ac})_{2}\right)$ precursor has been used to replace conventional lead halides. ${ }^{[24,25]}$ Ultra-smooth perovskite films were obtained after a short-duration and lowtemperature annealing. PCEs approaching $15 \%$ were achieved in the devices with a regular planar heterojunction structure. It was also noted that the use of additive, hypophosphorous acid, in the $\mathrm{Pb}(\mathrm{Ac})_{2}$-based precursor solutions could improve the device performance, leading to higher PCEs of $\sim 16 \%{ }^{[26]}$ Fullerene has been mixed into perovskites based on lead acetate and this was found to reduce hysteresis through the passivation effect of fullerene. ${ }^{[27]}$ The incorporation of $\mathrm{PbCl}_{2}$ as an additive into the lead acetate-based precursor solution has also been reported to form relatively large crystals with a PCE of $15 \%$ being achieved in planar perovskite solar cells using an inverted structure. ${ }^{[28]}$ To date, the devices based on lead acetate precursor have shown a relatively lower photovoltaic performance in comparison to the 


\section{WILEY-VCH}

reported highly efficient planar heterojunction perovskite solar cells based on lead halide precursors. ${ }^{[29-32]}$

Herein, we show a method to improve the efficiency of the planar heterojunction perovskite solar cells using $\mathrm{Pb}(\mathrm{Ac})_{2}$ as the lead source in the simple "one-step" deposition process. Methylammonium bromide (MABr) was used as an additive in the perovskite precursor solution containing stoichiometric amounts of $\mathrm{Pb}(\mathrm{Ac})_{2}$ and MAI. The addition of $\mathrm{MABr}$ in the precursor solution generated compact, pinhole-free perovskite films with improved uniformity and crystallinity. The charge carrier extraction at the interfaces between the perovskite layer and charge collection layers was also facilitated after the addition of trace amounts of MABr additive. A champion PCE of $18.3 \%$ was achieved with a stabilized output efficiency of $17.6 \%$ at the maximum power point. The optimized devices also exhibited negligible current density-voltage $(J-V)$ hysteresis when the MABr additive concentration was optimized.

\section{Results and Discussion}

\subsection{Device Optimization}

Figure 1a presents typical device architecture of the inverted planar heterojunction perovskite solar cells in this study. Poly(3,4-ethylenedioxythiophene)/poly(styrenesulfonate) (PEDOT:PSS, $25 \mathrm{~nm}$ ) served as the hole collection layer. [6,6]-phenyl-C61-butyric acid methyl ester $\left(\mathrm{PC}_{61} \mathrm{BM}, 40 \mathrm{~nm}\right)$ functioned as the electron extraction layer. Bathocuproine (BCP, $10 \mathrm{~nm}$ ) was used as hole blocking layer to avoid the hole-electron recombination at the perovskite/metal electrode interface. The $\mathrm{CH}_{3} \mathrm{NH}_{3} \mathrm{PbI}_{3}$ perovskite photoactive layers $(280 \mathrm{~nm})$ were prepared through the simple "one-step" deposition process based on the stoichiometric mixture of $\mathrm{Pb}(\mathrm{Ac})_{2}$ and MAI in dimethylformamide (DMF). MABr was used as the additive in the precursor solutions with varied molar ratios (mol\%) of $\mathrm{MABr}$ to $\mathrm{Pb}(\mathrm{Ac})_{2}$. 


\section{WILEY-VCH}

(a)

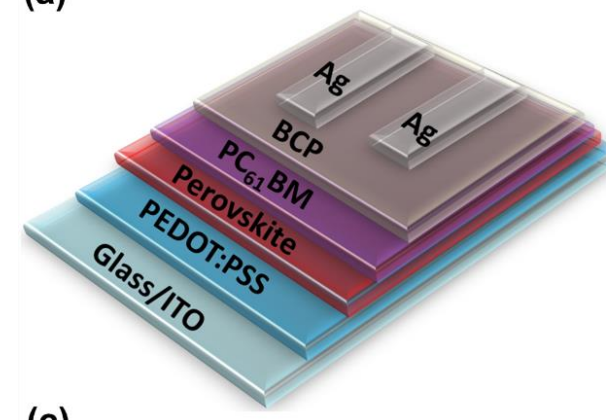

(c)

\begin{tabular}{llcccc}
\hline Devices & $\begin{array}{l}\text { Scan } \\
\text { direction }\end{array}$ & $\begin{array}{c}\boldsymbol{J}_{\text {sc }} \\
{\left[\mathbf{m A} \cdot \mathbf{c m}^{-2}\right]}\end{array}$ & $\begin{array}{c}V_{\text {oc }} \\
{[\mathbf{V}]}\end{array}$ & FF & $\begin{array}{c}\text { PCE } \\
{[\%]}\end{array}$ \\
\hline W/O MABr & Forward & 19.94 & 0.93 & 0.65 & 12.05 \\
& Reverse & 20.30 & 0.93 & 0.73 & 13.78 \\
With MABr & Forward & 22.50 & 0.97 & 0.80 & 17.46 \\
& Reverse & 22.50 & 0.97 & 0.80 & 17.46 \\
\hline
\end{tabular}

(b)

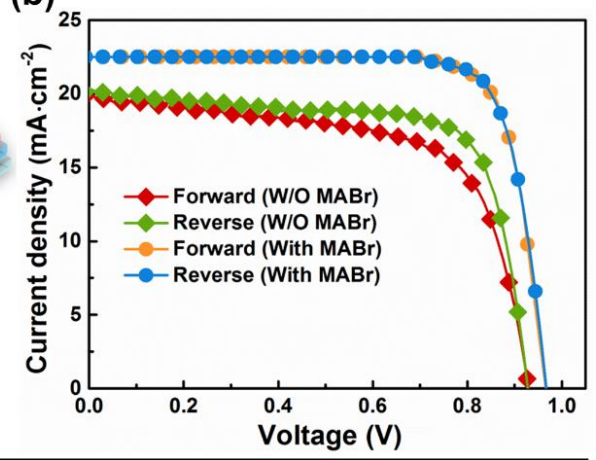

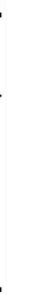

Figure 1. (a) Device configuration of the inverted planar perovskite solar cells. (b) Current density-voltage $(J-V)$ characterization for the devices fabricated without and with $1.5 \mathrm{~mol} \%$ $\mathrm{MABr}$ additive measured with forward and reverse scans under simulated AM 1.5G illumination of $100 \mathrm{~mW} \cdot \mathrm{cm}^{-2}$. (c) Performance summary for the devices in (b).

To explore the optimal amount of additive, the device fabrication process was well-controlled varying in only the concentrations of the additive. Table 1 summarizes the photovoltaic performance measured under simulated AM $1.5 \mathrm{G} 100 \mathrm{~mW} \cdot \mathrm{cm}^{-2}$ illumination. All devices were prepared from the same batch. The reference device without the MABr additive had a short-circuit current density $\left(J_{\mathrm{sc}}\right)$ of $20.30 \mathrm{~mA} \cdot \mathrm{cm}^{-2}$, open-circuit voltage $\left(V_{\mathrm{oc}}\right)$ of $0.93 \mathrm{~V}$, and fill factor (FF) of 0.73 , resulting in an overall PCE of $13.8 \%$. The device performance was continuously improved as long as the ratio of $\mathrm{MABr}$ was increased. Best performance was achieved when the MABr concentration was $1.5 \mathrm{~mol} \%$, yielding a $J_{\mathrm{sc}}$ of $22.50 \mathrm{~mA} \cdot \mathrm{cm}^{-2}, V_{\mathrm{oc}}$ of $0.97 \mathrm{~V}$, and FF of 0.80 , resulting in a PCE of $17.5 \%$. Further increasing the concentration of MABr did not improve device performance. Figure $1 \mathrm{~b}$ compares the hysteresis in the $J-V$ profile of devices fabricated without and with $\mathrm{MABr}(1.5 \mathrm{~mol} \%)$. The devices were measured with both the reverse scan (from forward bias to short circuit) and the forward scan (from 


\section{WILEY-VCH}

short circuit to forward bias). The reference device without MABr showed a hysteresis in the $J$ - $V$ profile. In contrast, negligible $J$ - $V$ hysteresis was observed after introducing $1.5 \mathrm{~mol} \%$ $\mathrm{MABr}$ as an additive.

Table 1. Performance summary of the inverted perovskite solar cells fabricated with different $\mathrm{MABr}$ additive concentrations under simulated $\mathrm{AM} 1.5 \mathrm{G} 100 \mathrm{~mW} \cdot \mathrm{cm}^{-2}$ illumination.

\begin{tabular}{lcccc}
\hline $\begin{array}{l}\text { MABr concentration } \\
{[\mathrm{mol} \%]}\end{array}$ & $\begin{array}{c}J_{\text {sc }} \\
{\left[\mathrm{mA} \cdot \mathrm{cm}^{-2}\right]}\end{array}$ & $\begin{array}{c}V_{\text {oc }} \\
{[\mathrm{V}]}\end{array}$ & FF & $\begin{array}{c}\text { PCE } \\
{[\%]}\end{array}$ \\
\hline 0 & 20.30 & 0.93 & 0.73 & 13.78 \\
0.5 & 20.96 & 0.94 & 0.75 & 14.78 \\
1.0 & 21.82 & 0.96 & 0.77 & 16.13 \\
1.5 & 22.50 & 0.97 & 0.80 & 17.46 \\
2.0 & 21.09 & 0.99 & 0.78 & 16.29 \\
\hline
\end{tabular}

Based on the perovskite active layers with MABr additive, a champion PCE of $18.3 \%$ was achieved after optimization, with a $J_{\mathrm{sc}}$ of $22.34 \mathrm{~mA} \cdot \mathrm{cm}^{-2}$, a $V_{\mathrm{oc}}$ of $1.00 \mathrm{~V}$ and a high FF of 0.82, as shown in Figure 2a. By contrast, the reference device without MABr additive had a highest best PCE of $14.3 \%$, with a $J_{\mathrm{sc}}$ of $20.28 \mathrm{~mA} \cdot \mathrm{cm}^{-2}, V_{\mathrm{oc}}$ of $0.95 \mathrm{~V}$ and FF of 0.74 . Figure $2 \mathrm{~b}$ shows the steady-state photocurrents and output efficiencies at the maximum power points. The reference device without $\mathrm{MABr}$ achieved a stabilized current density output of 17.40 $\mathrm{mA} \cdot \mathrm{cm}^{-2}$ (at the voltage of $0.80 \mathrm{~V}$ ), yielding a PCE of $13.9 \%$. For the device prepared with $\mathrm{MABr}$ additive, a stabilized PCE of $17.6 \%$ was obtained $\left(V=0.85 \mathrm{~V}, J=20.70 \mathrm{~mA} \cdot \mathrm{cm}^{-2}\right)$. To demonstrate the reproducibility of the device performance, Figure $2 \mathrm{c}$ shows the histograms of PCEs for the devices without and with an optimal MABr additive concentration (50 devices for each group). It is obvious that the use of $\mathrm{MABr}$ as an additive in the $\mathrm{Pb}(\mathrm{Ac})_{2}$-based precursor solution also improved the reproducibility of device performance. In addition, planar heterojunction perovskite solar cells with regular device structure (Figure S1, 


\section{WILEY-VCH}

Supporting Information) were also prepared to evaluate the perovskite films with $1.5 \mathrm{~mol} \%$ MABr additive. A remarkable PCE of $19.3 \%$ was achieved in the reverse scan with a $J_{\text {sc }}$ of $22.83 \mathrm{~mA} \cdot \mathrm{cm}^{-2}, V_{\text {oc }}$ of $1.10 \mathrm{~V}$ and FF of 0.77 . The same device gave a PCE of $15.2 \%$ in the forward scan with an average efficiency of $17.3 \%$ under simulated AM $1.5 \mathrm{G} 100 \mathrm{~mW} \cdot \mathrm{cm}^{-2}$ illumination.

(a)

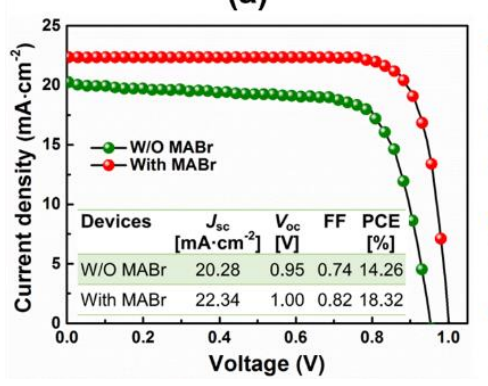

(b)

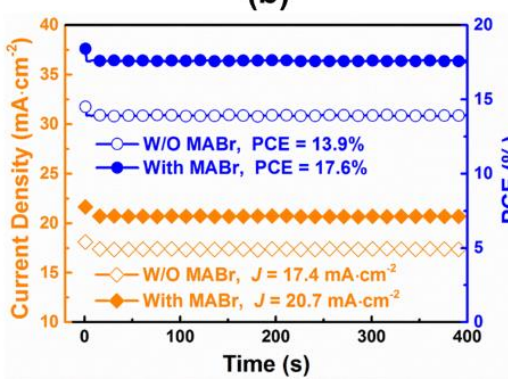

(c)

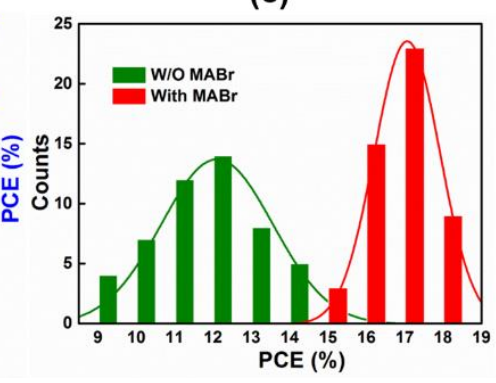

Figure 2. (a) $J-V$ curves of the best devices obtained without and with $1.5 \mathrm{~mol} \% \mathrm{MABr}$ additive in precursor solutions under AM $1.5 \mathrm{G}$ illumination of $100 \mathrm{~mW} \cdot \mathrm{cm}^{-2}$. (b) The steadystate photocurrents and output efficiencies of the devices at the maximum power points. (c) Histograms of the PCEs for the devices without and with MABr additive.

\subsection{Morphological Characterization}

To understand the enhanced device performance induced by $\mathrm{MABr}$ additive, the morphology of the perovskite films without and with $1.5 \mathrm{~mol} \% \mathrm{MABr}$ additive was characterized, as shown in Figure 3. Scanning electron microscopy (SEM) was used to visualize the surfaces of the perovskite films and the cross sections of the finished devices. Atomic force microscopy (AFM) was used to compare the surface roughnesses of the as-cast perovskite films. From top view SEM images shown in Figure 3a and 3d, both the films showed compact, pinhole-free coverages on the substrates. The surface uniformity of the film prepared with $\mathrm{MABr}$ additive was better than that without. The improved surface uniformity was further 


\section{WILEY-VCH}

confirmed by the AFM, as shown in Figure $3 \mathrm{~b}$ and $3 \mathrm{e}$. For the pristine reference perovskite film without the bromide additive (Figure $3 \mathrm{~b}$ ), the arithmetic average $\left(R_{\mathrm{a}}\right)$ and the root mean square $\left(R_{\mathrm{q}}\right)$ are 21.54 and $27.13 \mathrm{~nm}$, respectively within the scanned area. In contrast, the $R_{\mathrm{a}}$ and $R_{\mathrm{q}}$ values for the film prepared with $1.5 \mathrm{~mol} \% \mathrm{MABr}$ additive (Figure 3e) are $6.26 \mathrm{~nm}$ and $7.91 \mathrm{~nm}$, respectively. These are consistent with the top view SEM images in Figure 3a and 3d, indicating a much smoother film was produced using the MABr additive. Figure 3c and $3 \mathrm{f}$ compare the cross-sectional SEM images of the complete devices based on the perovskite films without and with $\mathrm{MABr}(1.5 \mathrm{~mol} \%)$ additive. It is noted that for films produced with the MABr additive, larger grain size and fewer lateral grain boundaries were obtained than those for the reference film. The grain size in the vertical direction for films produced with the MABr additive is comparable to the perovskite film thickness. This implies that the charge carriers can efficiently transport across the perovskite films and reach the corresponding electrode interfaces before recombination. ${ }^{[33]}$ In addition, conductive atomic force microscopy (c-AFM) in contact mode was also performed to investigate the distribution of film conductivity, as shown in Figure S3. The c-AFM results indicate that the film prepared with the MABr additive had more uniform current conduction and higher vertical current. These morphology characterization results indicate that the introduction of $\mathrm{MABr}$ additive in the $\mathrm{Pb}(\mathrm{Ac})_{2}$-based precursor solution can improve both the film uniformity and the perovskite crystallinity, two key requirements for high performance perovskite solar cells. ${ }^{[34]}$ 


\section{WILEY-VCH}
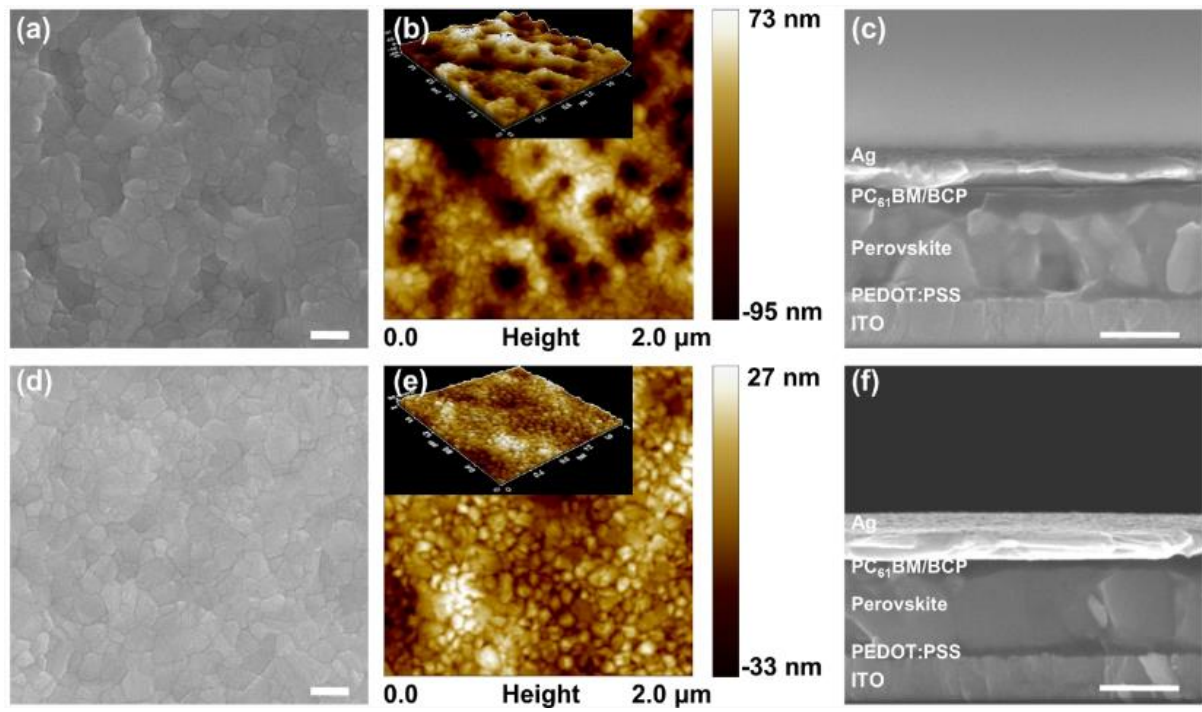

Figure 3. Morphology characterizations for the perovskite films without (a-c) and with (d-f) $1.5 \mathrm{~mol} \%$ MABr additive. (a,d) Top view scanning electron microscopy (SEM) images. (b,e) Atomic force microscopy (AFM) images (Inset: Three-dimensional surface topographical images). (c,f) SEM cross-sectional images of the finished devices. (Scale bar: $250 \mathrm{~nm}$ )

\subsection{Structural Characterization and Spectroscopic Studies}

Figure 4a compares the X-ray diffraction (XRD) spectra for the perovskite films prepared with different MABr additive concentrations. All the peaks in the XRD patterns could be indexed to the tetragonal crystal structure of $\mathrm{CH}_{3} \mathrm{NH}_{3} \mathrm{PbI}_{3} \cdot{ }^{[35]}$ It was also found that the intensities of the reflections changed when the $\mathrm{MABr}$ additive was used. For example, the intensity of the (110) peak reached the maximum when the $\mathrm{MABr}$ concentration was $\sim 1.5$ mol\%, paralleling the best device performance. In addition, the XRD patterns showed slight peak shift when MABr additive was used (Figure S4), indicating the existence of bromine. ${ }^{[36,37]}$ The trace amount of bromide additive in the perovskite film can also be detected by the ultraviolet-visible (UV-vis) absorption spectra. Figure $4 \mathrm{~b}$ gives the UV-vis absorption spectra for the perovskite films with different $\mathrm{MABr}$ additive concentrations. The inset of Figure $4 \mathrm{~b}$ shows the enlarged absorption spectra around the absorption onset. It is 


\section{WILEY-VCH}

evident that the blue shift of the absorption onset increases with increasing $\mathrm{MABr}$ concentration: from $780 \mathrm{~nm}$ for the film without $\mathrm{MABr}$ to $772 \mathrm{~nm}$ for the film with $2.0 \mathrm{~mol} \%$ MABr. This indicates the presence of a trace amount of a mixed halide perovskite which was generated based on the residual of bromide additive. The blue shift of absorption onset also implies the slight increase of optical bandgaps, which eventually contributes to the improved $V_{\text {oc. }}$
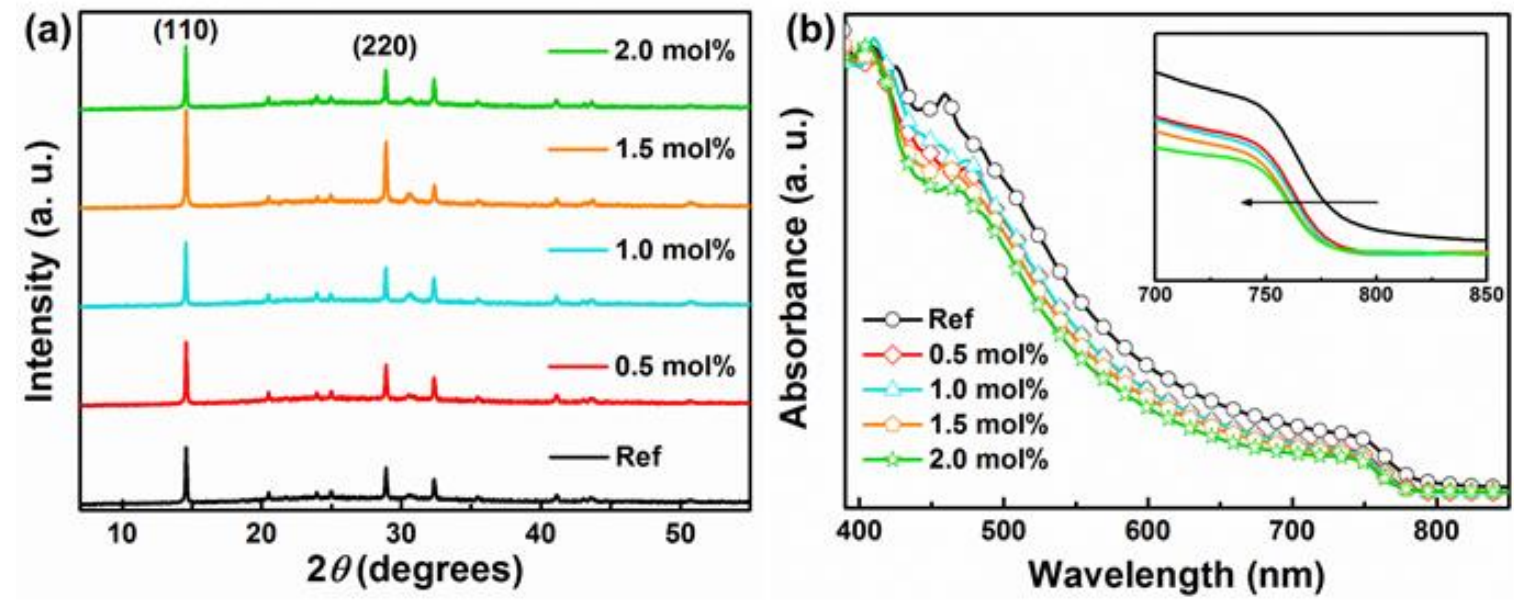

Figure 4. (a) X-ray diffraction (XRD) patterns and (b) ultraviolet-visible (UV-vis) absorption spectra for the 280 -nm-thick perovskite films prepared with $\mathrm{Pb}(\mathrm{Ac})_{2}$-based precursor solutions in the presence of $\mathrm{MABr}$ additive with different concentrations.

Figure 5 shows the photoluminescence (PL) spectra for the perovskite films processed with and without the MABr additive. The perovskite films were deposited on the ITO/PEDOT:PSS substrates and then covered by a $\mathrm{PC}_{61} \mathrm{BM}$ layer. Figure $5 \mathrm{a}$ and $5 \mathrm{~b}$ show the steady-state $\mathrm{PL}$ spectra for the samples excited from both the ITO side (Figure 5a) and $\mathrm{PC}_{61} \mathrm{BM}$ side (Figure 5b). The wavelength of excitation light was $470 \mathrm{~nm}$ which had limited penetration depth in the 280-nm-thick perovskite films. This ensured the study of the charge carrier behavior for the perovskites close to the interfaces between perovskite layer and charge collection layers. ${ }^{[38]}$ 


\section{WILEY-VCH}

For the reference sample without MABr additive, a PL peak at $782 \mathrm{~nm}$ was observed which was independent of the incident light directions. This indicates that the optical and charge carrier properties for perovskites close to the top and the bottom interfaces were not discernably. For the sample processed with the MABr additive, a blue-shifted PL peak (from 782 to $776 \mathrm{~nm}$ ) was observed when the incident light entered from the ITO side (Figure 5a). This was attributed to the existence of trace amount of mixed halide perovskite and is consistent with the blue shift in the UV-vis spectra. When the incident light came from the $\mathrm{PC}_{61} \mathrm{BM}$ side, a PL peak with slightly larger blue shift (from 782 to $771 \mathrm{~nm}$ ) was observed as shown in Figure 5b. The larger blue shift in the PL peak might be ascribed to a decrease in the surface trap states on the top surface of the perovskite film with $\mathrm{MABr}$ additive, because both the surface roughness and the surface conductance were improved by the additive as illustrated in Figure 3 and Figure S3. Moreover, it was noted that the addition of the MABr additive reduced the intensity of the steady-state PL peaks in both Figure 5a and 5b. This indicates that the charge carrier extractions at both the top and bottom interfaces were enhanced by MABr additive.

The interfacial interaction was further investigated by the time-resolved photoluminescence (TRPL) decay measurements. TRPL measurement has been successfully used to determine exciton lifetime, diffusion rate and diffusion length. ${ }^{[39,40]}$ It can also be used to explore the charge carrier extraction at the interface between charge collection layers and the perovskite layer. In this work, TRPL measurement was performed to compare the perovskite active layers obtained without and with $\mathrm{MABr}$ at both the hole and electron extraction interfaces. The samples and film excitation conditions for TRPL measurements were the same as those used in steady-state PL measurements. The TRPL decays were acquired at the emission wavelength of $767 \mathrm{~nm}$. The observed PL decays were fit with two exponential decay curves to yield the lifetimes of excitons or carriers according to the one-dimensional diffusion model 


\section{WILEY-VCH}

(the longer lifetime was used). ${ }^{[38]}$ Figure $5 \mathrm{c}$ and $5 \mathrm{~d}$ show the TRPL results. The reference perovskite film prepared without $\mathrm{MABr}$ had carrier lifetimes of $41.9 \mathrm{~ns}$ (from ITO side) and 22.7 ns (from $\mathrm{PC}_{61} \mathrm{BM}$ ). After introducing the $\mathrm{MABr}$ additive, reduced carrier lifetimes of $32.3 \mathrm{~ns}$ (from ITO side) and $16.8 \mathrm{~ns}$ (from $\mathrm{PC}_{61} \mathrm{BM}$ ) were obtained. Compared to those of the pure perovskite films, the shorter lifetimes obtained for the perovskite film with $\mathrm{MABr}$ suggests that the bromide additive accelates charge extraction from perovskite to charge collection layers. ${ }^{[26,41]}$ This is consitent with the reduced steady-state PL peak intensity and directly translates into the improved device performance.
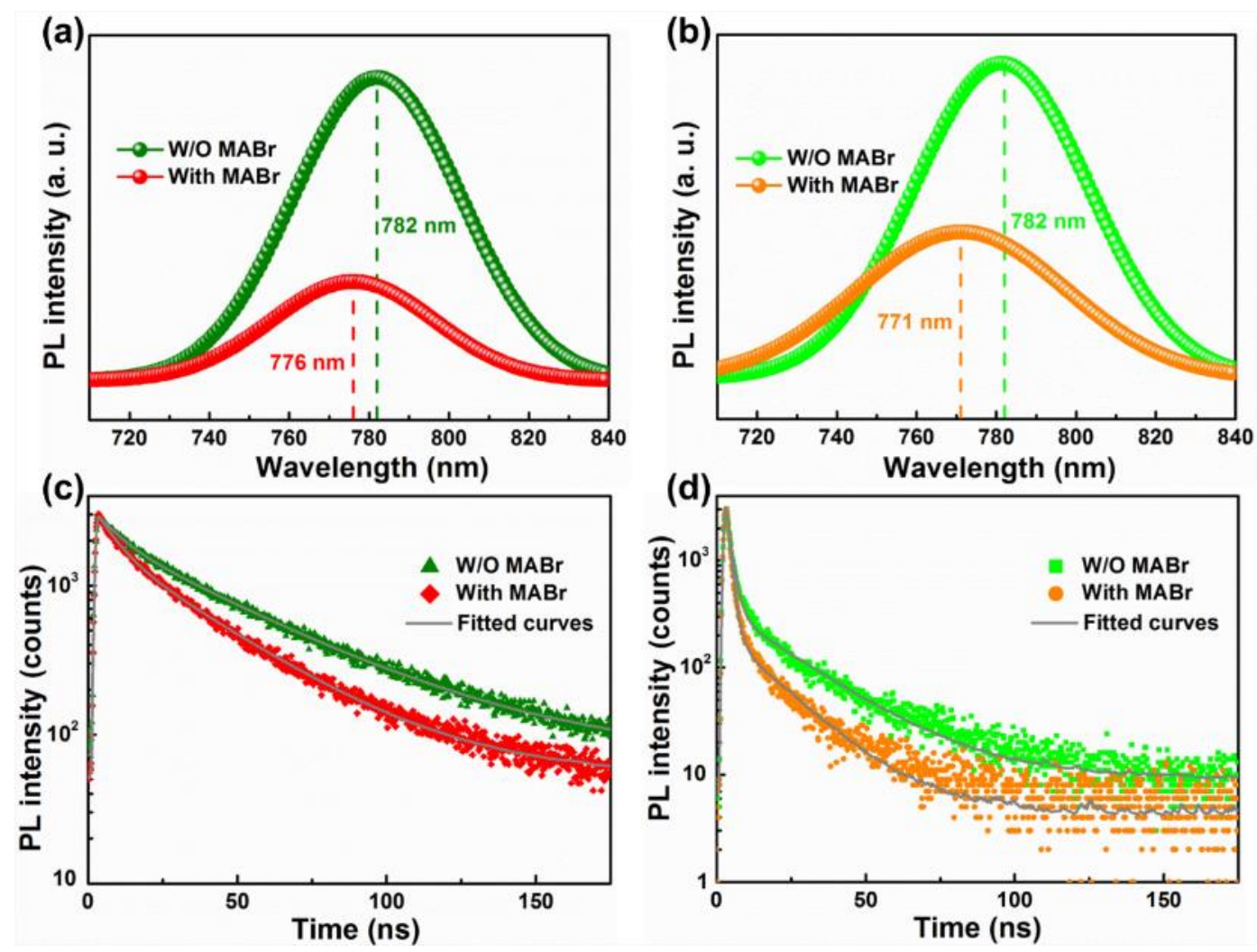

Figure 5. (a,b) Steady-state and (c,d) time-resolved photoluminescence (PL) spectra of the perovskite films (Film architecture: ITO/PEDOT:PSS/perovskite (w/o and with MABr) $\left./ \mathrm{PC}_{61} \mathrm{BM}\right)$ measured at $767 \mathrm{~nm}$. The films were excited with $470 \mathrm{~nm}$ excitation laser light from both the ITO side $(\mathrm{a}, \mathrm{c})$ and the $\mathrm{PC}_{61} \mathrm{BM}$ side $(\mathrm{b}, \mathrm{d})$. 


\section{WILEY-VCH}

\section{Conclusion}

In conclusion, we have used $\mathrm{MABr}$ as an additive for the perovskite film prepared with $\mathrm{Pb}(\mathrm{Ac})_{2}$ precursor. It is evident appropriate amounts of $\mathrm{MABr}$ in the $\mathrm{Pb}(\mathrm{Ac})_{2}$-based procursor solution can not only improve the film morphology and crystallinity, but also tune the optical and electrical properties of the perovskite photoactive layer. Charge carrier extraction at the interfaces between the perovskite layer and charge collection layers was also enhanced, as judged by PL quenching measurements. A champion power conversion efficiency of $18.32 \%$ was achieved in the inverted planar heterojunction perovskite solar cells based on the lead acetate precursor, with the stabilized output efficiency of $17.60 \%$ at maximum power point. The optimized devices also showed negligible $J$ - $V$ hysteresis. These results indicate that lead acetate can be a promising precursor to achieve highly efficient planar heterojunction perovskite solar cells, and further improvements through subtle tuning of chemical composition are likely to be feasible.

\section{Experimental Section}

Materials: Methylamine iodide (MAI) and methylamine bromide (MABr) was synthesized with methylamine (MA) and hydrohalic acid (HX) through the method reported by the previous literature. ${ }^{[42]}$ Lead acetate $\left(\mathrm{Pb}(\mathrm{Ac})_{2}\right)$ was purchased from Sinopharm Group Company and used as received. Poly(3,4-ethylenedioxythiophene):poly(styrenesulfonate) (PEDOT:PSS, P VP AI4083) was purchased from Heraeus Clevios. [6,6]-phenyl C61-butyric acid methyl ester ( $\left.\mathrm{PC}_{61} \mathrm{BM}\right)$ was purchased from C-Nano Tech. 2,9-dimethyl-4,7-diphenyl1,10-phenanthroline (BCP) and 2,2',7,7'-tetrakis[N,N-di(4-methoxyphenyl)amino]-9,9'spirobifluorene (Spiro-OMeTAD) were purchased from SunaTech Inc. All other liquid reagents, such as $N, N$-Dimethylformamide (DMF), 2-propanol (IPA), and chlorobenzene (CB), were purchased from commercial sources (Across) and used as received. 


\section{WILEY-VCH}

Inverted Structure Perovskite Solar Cells: The devices were manufactured on the prepatterned glass/ITO substrates $(1.5 \mathrm{~cm} \times 1.5 \mathrm{~cm}, 15 \Omega / \square)$, which were ultrasonically cleaned with diluted detergent, deionized water, acetone, and IPA in succession. Before spin-coating, the glass/ITO substrates were treated by UV-Ozone for $7 \mathrm{~min}$. Then PEDOT:PSS was spincoated onto the ITO substrates at $4000 \mathrm{rpm}$ for $30 \mathrm{~s}$. The samples were then annealed at $130{ }^{\circ} \mathrm{C}$ for $20 \mathrm{~min}$ in ambient atmosphere and transferred into the glovebox filled with $\mathrm{N}_{2}$. To create the perovskite precursor solution, $\mathrm{MAI}$ and $\mathrm{Pb}(\mathrm{Ac})_{2}$ were dissolved in anhydrous $\mathrm{DMF}$ at a 3:1 molar ratio with a final concentration of $46 \mathrm{wt} \%$ before adding varied molar ratios of $\mathrm{MABr}$ to $\mathrm{Pb}(\mathrm{Ac})_{2}$ in $\mathrm{DMF}$. The precursor solution was spin-coated at $4000 \mathrm{rpm}$ for $60 \mathrm{~s}$, and then the samples were directly placed onto a hot plate at $80{ }^{\circ} \mathrm{C}$ for $5 \mathrm{~min}$. After the as-heated perovskite films cooled down to room temperature, a $30 \mu \mathrm{L}$ of $\mathrm{PC}_{61} \mathrm{BM}\left(20 \mathrm{mg} \cdot \mathrm{mL}^{-1}\right.$ in $\left.\mathrm{CB}\right)$ solution was spin-coated on the top of perovskite layer at $1000 \mathrm{rpm}$ for $30 \mathrm{~s}$ to form an electron collection layer. Afterwards, BCP in IPA was spin-coated at $1000 \mathrm{rpm}$ for $30 \mathrm{~s}$. Finally, metal silver $(80 \mathrm{~nm})$ electrode was thermally evaporated in the vacuum chamber with the base pressure of $<4 \times 10^{-4} \mathrm{~Pa}$ though a shadow mask.

Regular Structure Perovskite Solar Cells: The $\mathrm{TiO}_{x}$ nanoparticle precursor solution was prepared based on our reported literature. ${ }^{[43,44]}$ Then the solution was spin-coated on precleaned and patterned glass/FTO substrates at $3000 \mathrm{rpm}$ for $60 \mathrm{~s}$, then thermally annealed at $500{ }^{\circ} \mathrm{C}$ for $30 \mathrm{~min}$ in the air to build a $\mathrm{TiO}_{x}$ layer. The perovskite active layer was fabricated via the same process as described above for the inverted structure solar cells, and heated at $100{ }^{\circ} \mathrm{C}$ to form the desired crystals. $80 \mathrm{mg}$ of Spiro-OMeTAD, $17.5 \mu \mathrm{L}$ of lithium bis(trifluoromethanesulfonyl)-imide (Li-TFSI) solution (520 $\mathrm{mg}$ of Li-TFSI in $1 \mathrm{~mL}$ of acetonitrile) and $28.5 \mu \mathrm{L}$ of 4-tert-butylpyridine were all dissolved in $1 \mathrm{~mL}$ of $\mathrm{CB}$ and the solution was then coated at $2000 \mathrm{rpm}$ for $40 \mathrm{~s}$ on perovskite active layer as the hole collection 


\section{WILEY-VCH}

layer. Similarly, metal gold electrode of $80 \mathrm{~nm}$ was thermally evaporated in the vacuum chamber with the base pressure of $<4 \times 10^{-4} \mathrm{~Pa}$ though a shadow mask.

Characterization of perovskite solar cells: The cells (active area: $0.09 \mathrm{~cm}^{2}$ ) were irradiated under $100 \mathrm{~mW} \cdot \mathrm{cm}^{-2}$ by a $150 \mathrm{~W}$ class AAA solar simulator (XES-40S1, SAN-EI) with an AM 1.5G filter. The light intensity of $100 \mathrm{~mW} \cdot \mathrm{cm}^{-2}$ was determined by a standard monocrystalline silicon photodiode calibrated by the Newport TAC-PV lab. The $J-V$ curves were measured with a Keithley 2400 source-measure unit. The EQE spectra were measured in air using a lock-in amplifier coupled with a monochromator (Crowntech, Qtest Station 2000, USA). The light intensity from the monochromator was calibrated by using a standard monocrystalline Si photovoltaic cell. To ensure an accurate illumination area, the champion devices were also tested using an aperture mask (an area of $0.07 \mathrm{~cm}^{2}$ ). The measurements of the inverted structure devices were carried out in a glove box filled with $\mathrm{N}_{2}$ at room temperature. The regular structure devices were measured in the ambient atmosphere. All of the devices were tested without encapsulation.

Other Characterizations: Scanning electron microscopy (SEM) images were obtained through a field-emission SEM (FEI Nova_Nano SEM 430). The atomic force microscopy (AFM) images were collected by an atomic force microscope in non-contact mode from Thchcomp (XE-100, Park Systems, Korea). The conductive atomic force microscopy (c-AFM) images were collected by the same equipment in contact mode. Given the small values of surface current, the mapping of current value vs color is built by evaluating the logarithm of current value. The film thickness was measured by stylus profilometry (Bruker Dektak XT, Germany). The X-ray diffractmeter (XRD) samples prepared on ITO/PEDOT:PSS substrates were characterized by Mini Flex 600 (Rigaku, Japan). The ultraviolet-visible (UV-vis) absorption spectra of perovskite films on ITO/PEDOT:PSS were performed by an spectrophotometer (Agilent 8453, USA). The steady-state and time-resolved photoluminescence (PL) spectra 


\section{WILEY-VCH}

were measured at $767 \mathrm{~nm}$ upon excitation at $470 \mathrm{~nm}$ via a fluorescence spectrophotometer

(FLS980, Edinburgh Instruments, England). The electrochemical impedance spectroscopy (EIS) was carried out by an electrochemical workstation (Autolab PGSTAT302N, Metrohm, Switzerland) and the results were fitted with the software named Nova.

\section{Supporting Information}

Supporting Information is available from the Wiley Online Library or from the author.

\section{Acknowledgements}

L.Z. and D.L. contributed equally to this work. This work was financially supported by the National Natural Science Foundation of China (61377025, 91433203, and 11121091), the 973 Program of China (2015CB932203) and the Young 1000 Talents Global Recruitment Program of China. F.L. and T.P.R. were supported by the U.S. Office of Naval Research under contract N00014-15-1-2244. Q.H. also received support from the Advanced Light Source Doctoral Fellowship in Residence at the Lawrence Berkeley National Laboratory. The authors thank Prof. Shufeng Wang and Mr. Yu Li for the photoluminescence measurements.

Received: ((will be filled in by the editorial staff))

Revised: ((will be filled in by the editorial staff)) Published online: ((will be filled in by the editorial staff))

[1] A. Kojima, K. Teshima, Y. Shirai, T. Miyasaka, J. Am. Chem. Soc. 2009, 131, 6050.

[2] S. Kazim, M. K. Nazeeruddin, M. Gratzel, S. Ahmad, Angew. Chem. Int. Ed. 2014, 53, 2812.

[3] S. D. Stranks, G. E. Eperon, G. Grancini, C. Menelaou, M. J. Alcocer, T. Leijtens, L. M. Herz, A. Petrozza, H. J. Snaith, Science 2013, 342, 341.

[4] C. Wehrenfennig, G. E. Eperon, M. B. Johnston, H. J. Snaith, L. M. Herz, Adv. Mater. 2014, 26, 1584.

[5] A. Mei, X. Li, L. Liu, Z. Ku, T. Liu, Y. Rong, M. Xu, M. Hu, J. Chen, Y. Yang, M. Gratzel, H. Han, Science 2014, 345, 295.

[6] W. S. Yang, J. H. Noh, N. J. Jeon, Y. C. Kim, S. Ryu, J. Seo, S. I. Seok, Science 2015, $348,1234$. 


\section{WILEY-VCH}

[7] D. Bi, W. Tress, M. I. Dar, P. Gao, J. Luo, C. Renevier, K. Schenk, A. Abate, F. Giordano, J. P. C. Baena, Science Advances 2016, 2, e1501170.

[8] H. S. Kim, C. R. Lee, J. H. Im, K. B. Lee, T. Moehl, A. Marchioro, S. J. Moon, R. Humphry-Baker, J. H. Yum, J. E. Moser, M. Gratzel, N. G. Park, Scientific reports 2012, 2, 591.

[9] M. M. Lee, J. Teuscher, T. Miyasaka, T. N. Murakami, H. J. Snaith, Science 2012, 338, 643.

[10] Y. Zhao, K. Zhu, J. Am. Chem. Soc. 2014, 136, 12241.

[11] Z. Xiao, C. Bi, Y. Shao, Q. Dong, Q. Wang, Y. Yuan, C. Wang, Y. Gao, J. Huang, Energy Environ. Sci. 2014, 7, 2619.

[12] N. J. Jeon, J. H. Noh, Y. C. Kim, W. S. Yang, S. Ryu, S. I. Seok, Nat. Mater. 2014, 13, 897.

[13] T. Zhang, M. Yang, Y. Zhao, K. Zhu, Nano Lett. 2015, 15, 3959.

[14] J. Y. Jeng, Y. F. Chiang, M. H. Lee, S. R. Peng, T. F. Guo, P. Chen, T. C. Wen, Adv. Mater. 2013, 25, 3727.

[15] Y. Zhou, O. S. Game, S. Pang, N. P. Padture, J. Phys. Chem. Lett. 2015, 6, 4827.

[16] M. Liu, M. B. Johnston, H. J. Snaith, Nature 2013, 501, 395.

[17] J. Burschka, N. Pellet, S. J. Moon, R. Humphry Baker, P. Gao, M. K. Nazeeruddin, M. Gratzel, Nature 2013, 499, 316.

[18] T. Liu, Q. Hu, J. Wu, K. Chen, L. Zhao, F. Liu, C. Wang, H. Lu, S. Jia, T. Russell, R. Zhu, Q. Gong, Adv. Energy Mater. 2015, 1501890.

[19] M. Xiao, F. Huang, W. Huang, Y. Dkhissi, Y. Zhu, J. Etheridge, A. Gray-Weale, U. Bach, Y. B. Cheng, L. Spiccia, Angew. Chem. Int. Ed. 2014, 53, 9898.

[20] N. J. Jeon, J. H. Noh, W. S. Yang, Y. C. Kim, S. Ryu, J. Seo, S. I. Seok, Nature 2015, $517,476$. 


\section{WILEY-VCH}

[21] Z. Zhou, Z. Wang, Y. Zhou, S. Pang, D. Wang, H. Xu, Z. Liu, N. P. Padture, G. Cui, Angew. Chem. Int. Ed. 2015, 54, 9705.

[22] Q. Jiang, D. Rebollar, J. Gong, E. L. Piacentino, C. Zheng, T. Xu, Angew. Chem. Int. Ed. 2015, 54, 7617.

[23] F. K. Aldibaja, L. Badia, E. Mas Marzá, R. S. Sánchez, E. M. Barea, I. Mora Sero, J. Mater. Chem. A 2015, 3, 9194.

[24] W. Zhang, M. Saliba, D. T. Moore, S. K. Pathak, M. T. Horantner, T. Stergiopoulos, S. D. Stranks, G. E. Eperon, J. A. Alexander Webber, A. Abate, A. Sadhanala, S. Yao, Y. Chen, R. H. Friend, L. A. Estroff, U. Wiesner, H. J. Snaith, Nat. Commun. 2015, 6, 6142.

[25] H. Zhu, Y. Fu, F. Meng, X. Wu, Z. Gong, Q. Ding, M. V. Gustafsson, M. T. Trinh, S. Jin, X. Y. Zhu, Nat. Mater. 2015, 14, 636.

[26] W. Zhang, S. Pathak, N. Sakai, T. Stergiopoulos, P. K. Nayak, N. K. Noel, A. A. Haghighirad, V. M. Burlakov, D. W. deQuilettes, A. Sadhanala, W. Li, L. Wang, D. S. Ginger, R. H. Friend, H. J. Snaith, Nat. Commun. 2015, 6, 10030.

[27] J. Xu, A. Buin, A. H. Ip, W. Li, O. Voznyy, R. Comin, M. Yuan, S. Jeon, Z. Ning, J. J. McDowell, P. Kanjanaboos, J. P. Sun, X. Lan, L. N. Quan, D. H. Kim, I. G. Hill, P. Maksymovych, E. H. Sargent, Nat. Commun. 2015, 6, 7081.

[28] J. Qing, H. T. Chandran, Y. H. Cheng, X. K. Liu, H. W. Li, S. W. Tsang, M. F. Lo, C. S. Lee, ACS Appl. Mater. Interfaces 2015, 7, 23110.

[29] H. Zhou, Q. Chen, G. Li, S. Luo, T.-b. Song, H.-S. Duan, Z. Hong, J. You, Y. Liu, Y. Yang, Science 2014, 345, 542.

[30] N. Ahn, D. Y. Son, I. H. Jang, S. M. Kang, M. Choi, N. G. Park, J. Am. Chem. Soc. $\mathbf{2 0 1 5}, 137,8696$.

[31] W. Chen, Y. Wu, Y. Yue, J. Liu, W. Zhang, X. Yang, H. Chen, E. Bi, I. Ashraful, M. Grätzel, Science 2015, 350, 944.

[32] Y. Shao, Y. Yuan, J. Huang, Nature Energy 2016, 1, 15001. 


\section{WILEY-VCH}

[33] Y. Deng, E. Peng, Y. Shao, Z. Xiao, Q. Dong, J. Huang, Energy Environ. Sci. 2015, 8, 1544.

[34] T. Salim, S. Sun, Y. Abe, A. Krishna, A. C. Grimsdale, Y. M. Lam, J. Mater. Chem. A 2015, 3, 8943 .

[35] K. Liang, D. B. Mitzi, M. T. Prikas, Chem. mater. 1998, 10, 403.

[36] J. H. Noh, S. H. Im, J. H. Heo, T. N. Mandal, S. I. Seok, Nano Lett. 2013, 13, 1764.

[37] M. Ibrahim Dar, M. Abdi-Jalebi, N. Arora, T. Moehl, M. Gratzel, M. K. Nazeeruddin, Adv. Mater. 2015, 27, 7221.

[38] Y. Shao, Z. Xiao, C. Bi, Y. Yuan, J. Huang, Nat. Commun. 2014, 5, 5784.

[39] G. Xing, N. Mathews, S. Sun, S. S. Lim, Y. M. Lam, M. Grätzel, S. Mhaisalkar, T. C. Sum, Science 2013, 342, 344.

[40] P. E. Shaw, A. Ruseckas, I. D. Samuel, Adv. Mater. 2008, 20, 3516.

[41] A. Buin, P. Pietsch, J. Xu, O. Voznyy, A. H. Ip, R. Comin, E. H. Sargent, Nano Lett. 2014, 14, 6281.

[42] Q. Hu, J. Wu, C. Jiang, T. Liu, X. Que, R. Zhu, Q. Gong, ACS nano 2014, 8, 10161.

[43] Q. Hu, Y. Liu, Y. Li, L. Ying, T. Liu, F. Huang, S. Wang, W. Huang, R. Zhu, Q. Gong, J. Mater. Chem. A 2015, 3, 18483.

[44] T. Liu, K. Chen, Q. Hu, J. Wu, D. Luo, S. Jia, R. Zhu, Q. Gong, Chin. Chem. Lett. 2015, 26, 1518. 


\section{WILEY-VCH}

\section{Table of Contents:}

High-performance inverted perovskite solar cells based on lead acetate precursor are demonstrated with power conversion efficiency exceeding $18 \%$ and stabilized output efficiency of $17.6 \%$. Methylammonium bromide was utilized as additive into the lead acetate precursor solutions, leading to the perovskite films with improved performance.

Keywords: perovskite solar cells, inverted planar heterojunction, lead acetate, additive, high efficiency

Lichen Zhao, Deying Luo, Jiang Wu, Qin Hu, Wei Zhang, Ke Chen, Tanghao Liu, Yi Liu, Yifei Zhang, Feng Liu, Thomas P. Russell, * Henry J. Snaith, Rui Zhu,* and Qihuang Gong

High-Performance Inverted Planar Heterojunction Perovskite Solar Cells Based on Lead Acetate Precursor with Efficiency Exceeding $18 \%$

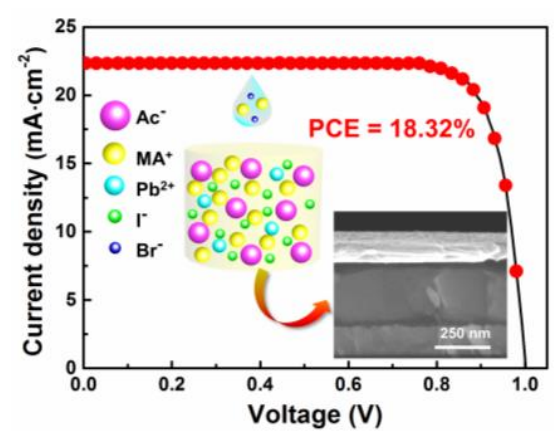




\section{WILEY-VCH}

Copyright WILEY-VCH Verlag GmbH \& Co. KGaA, 69469 Weinheim, Germany, 2013.

\section{Supporting Information}

High-Performance Inverted Planar Heterojunction Perovskite Solar Cells Based on Lead Acetate Precursor with Efficiency Exceeding 18\%

Lichen Zhao, Deying Luo, Jiang Wu, Qin Hu, Wei Zhang, Ke Chen, Tanghao Liu, Yi Liu, Yifei Zhang, Feng Liu, Thomas P. Russell, * Henry J. Snaith, Rui Zhu, * and Qihuang Gong 


\section{WILEY-VCH}

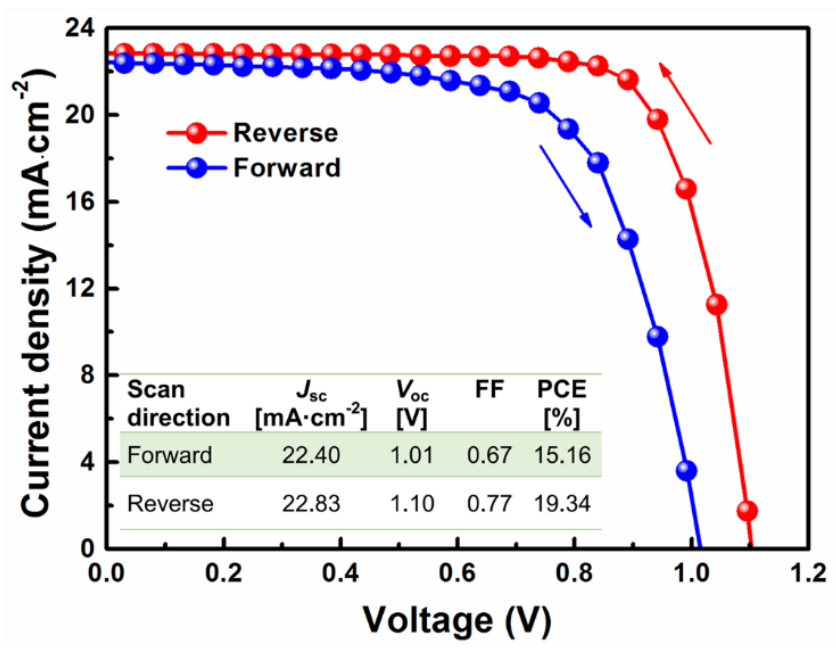

Figure S1. $J$ - $V$ curves of the regular planar heterojunction perovskite solar cell composed of glass/FTO/c-TiO $2 /$ perovskite thin film/spiro-OMeTAD/Au obtained in the presence of 1.5 mol\% MABr additive measured with forward and reverse scans under simulated AM 1.5G illumination of $100 \mathrm{~mW} \cdot \mathrm{cm}^{-2}$. The $\mathrm{c}-\mathrm{TiO}_{2}$ is a compact $\mathrm{TiO}_{2}$ layer. 


\section{WILEY-VCH}

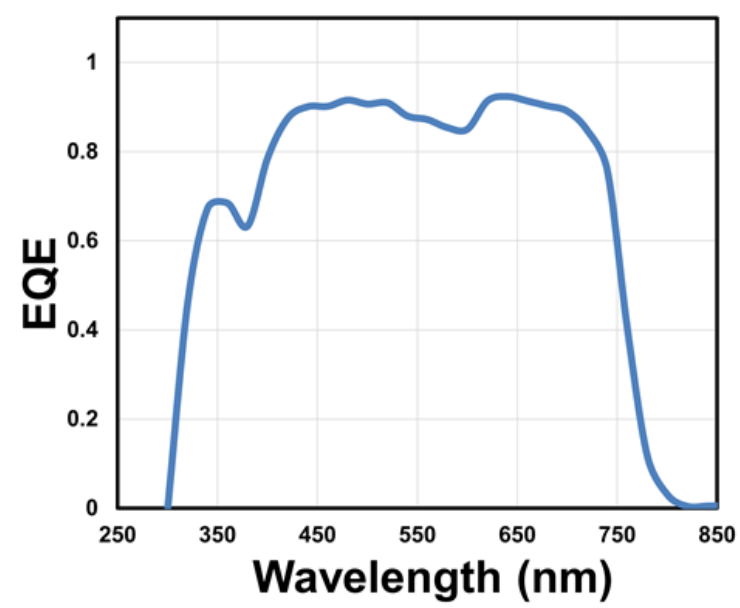

Figure S2. EQE spectrum for the champion device fabricated with $1.5 \mathrm{~mol} \% \mathrm{MABr}$. 


\section{WILEY-VCH}

(a)

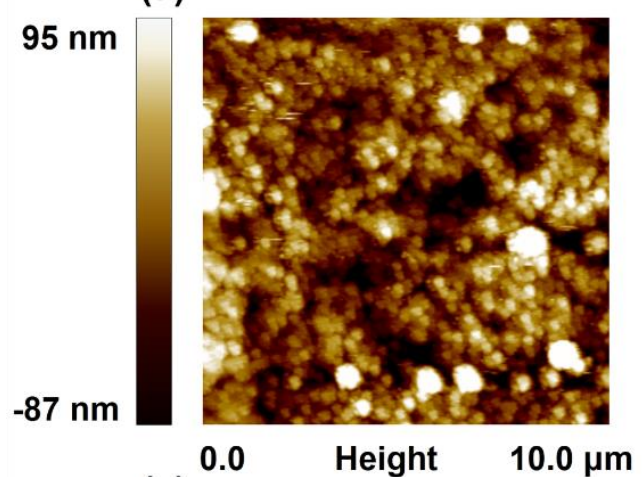

(c)

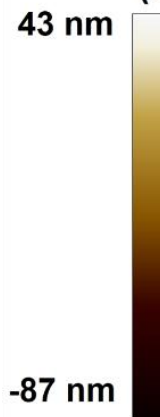

(b)

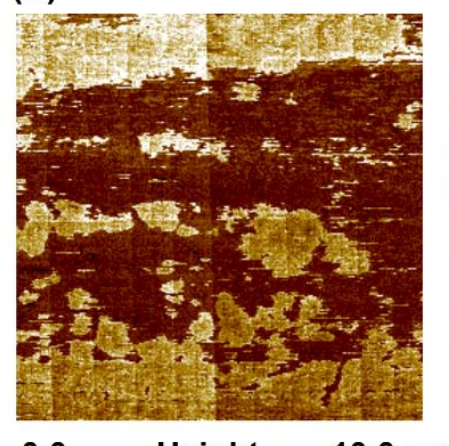

(d)

Height $\quad 10.0 \mu \mathrm{m}$
$6.331 \mathrm{nA}$

$6.326 \mathrm{nA}$

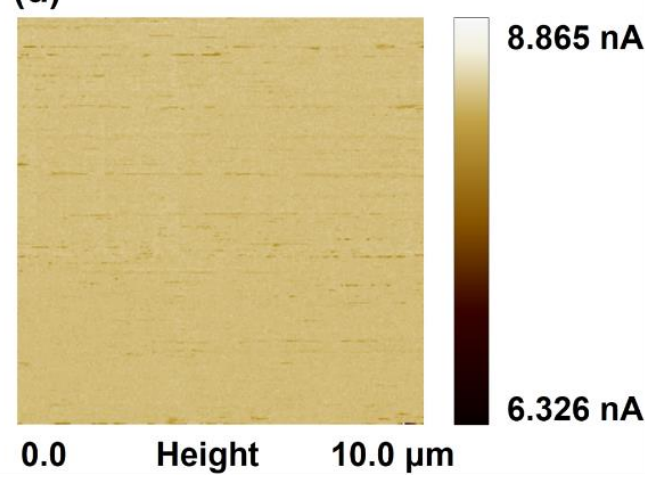

Figure S3. Conductive atomic force microscopy (c-AFM) characterizations in contact mode for the perovskite films without (a,b) and with (c,d) $1.5 \mathrm{~mol} \% \mathrm{MABr}$ additive. (a,c) Surface AFM images. (b,d) C-AFM images. Given the small values of surface current, the mapping of current value vs color is built by evaluating the logarithm of current value. 


\section{WILEY-VCH}

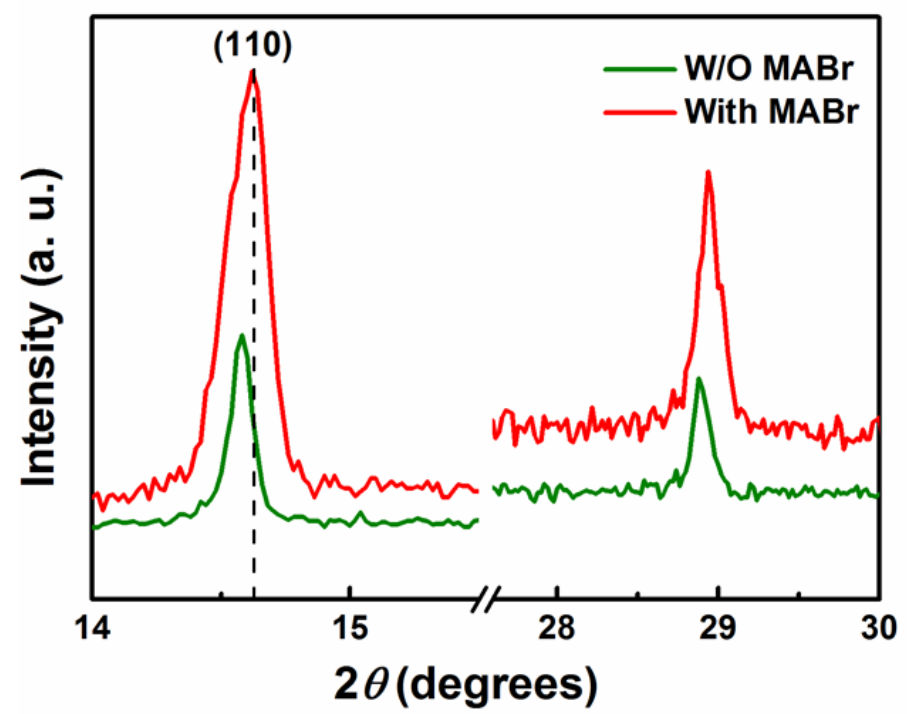

Figure S4. XRD patterns for the $\sim 280$-nm-thick perovskite films prepared with $\mathrm{Pb}(\mathrm{Ac})_{2}$ based precursor solutions with and without $\mathrm{MABr}$ additive. A relative peak shift of $0.046^{\circ}$ was observed for the film obtained in the presence of MABr. 


\section{WILEY-VCH}

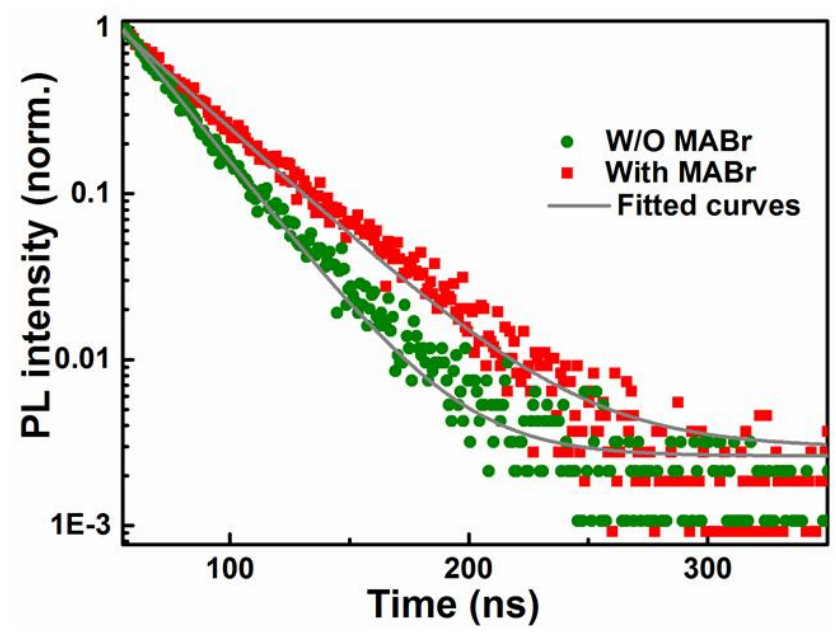

Figure S5. TRPL spectra of the perovskite films without and with $\mathrm{MABr}$ on the bare glass substrates measured at $767 \mathrm{~nm}$.

TRPL measurements were also carried out for the perovskite layers with and without MABr on the bare glass substrates wihout any interfatial layers. This ensured that the lifeimes measured did belong to the charge carriers inside the perovskite. The perovskite film prepared with $1.5 \mathrm{~mol} \% \mathrm{MABr}$ had longer lifetime than the reference film without MABr. This indicates the enhancement of charge carrier transferring inside the perovskite films induced by $\mathrm{MABr}$ additive. 


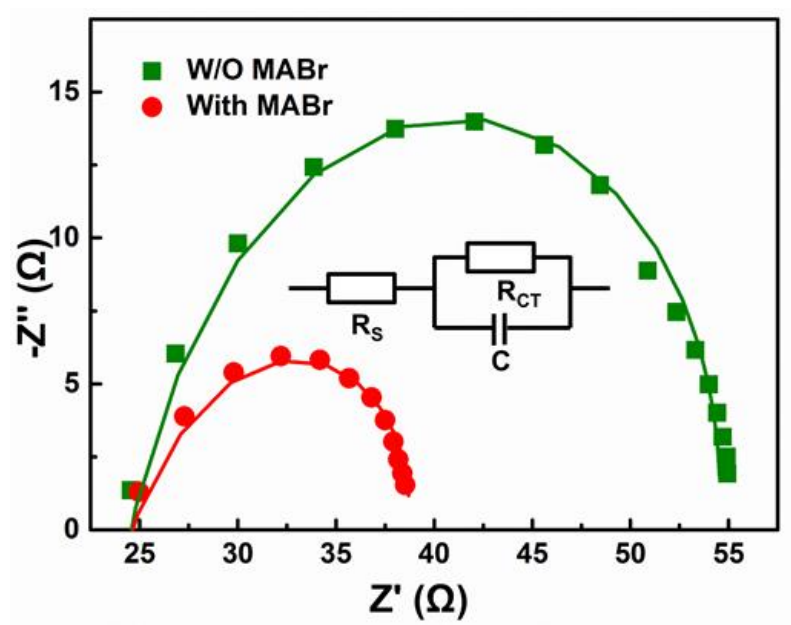

Figure S6. Nyquist plots under the light intensity of $100 \mathrm{~mW} \cdot \mathrm{cm}^{-2}$ at $0.97 \mathrm{~V}$ for inverted perovskite solar cells obtained without and with $1.5 \mathrm{~mol} \% \mathrm{MABr}$ additive. The electrochemical impedance spectroscopy (EIS) results were fitted with corresponding equivalent circuits. The series resistance $\left(\mathrm{R}_{\mathrm{S}}\right)$ almost unchanged after introducing MABr, but the charge transfer resistance $\left(\mathrm{R}_{\mathrm{CT}}\right)$ became lower. $\mathrm{R}_{\mathrm{CT}}$ of 17.7 and $33.1 \Omega$ was obtained for the device prepared with $1.5 \mathrm{~mol} \% \mathrm{MABr}$ and the reference device without $\mathrm{MABr}$, respectively. Smaller $\mathrm{R}_{\mathrm{CT}}$ implies a better contact between perovskite and eletron block layer, and enhanced charge carrier ransferring, thus contributed to the improvement in power conversion efficiency. ${ }^{[\mathrm{S} 1]}$ This is consistent with the results of steady-state PL and TRPL.

[S1] K. Wang, C. Liu, P. Du, H. L. Zhang, X. Gong, Small 2015, 11, 3369. 